\title{
Evaluation and Comparison of Efficacy of the Surface Disinfectants Used in a Tertiary Care Hospital, India
}

\author{
Namrata K. Bhosale* \\ Annai Theresa apartment, Block 2, St. Paulpet, Lawspet, Pondicherry, India \\ *Corresponding author
}

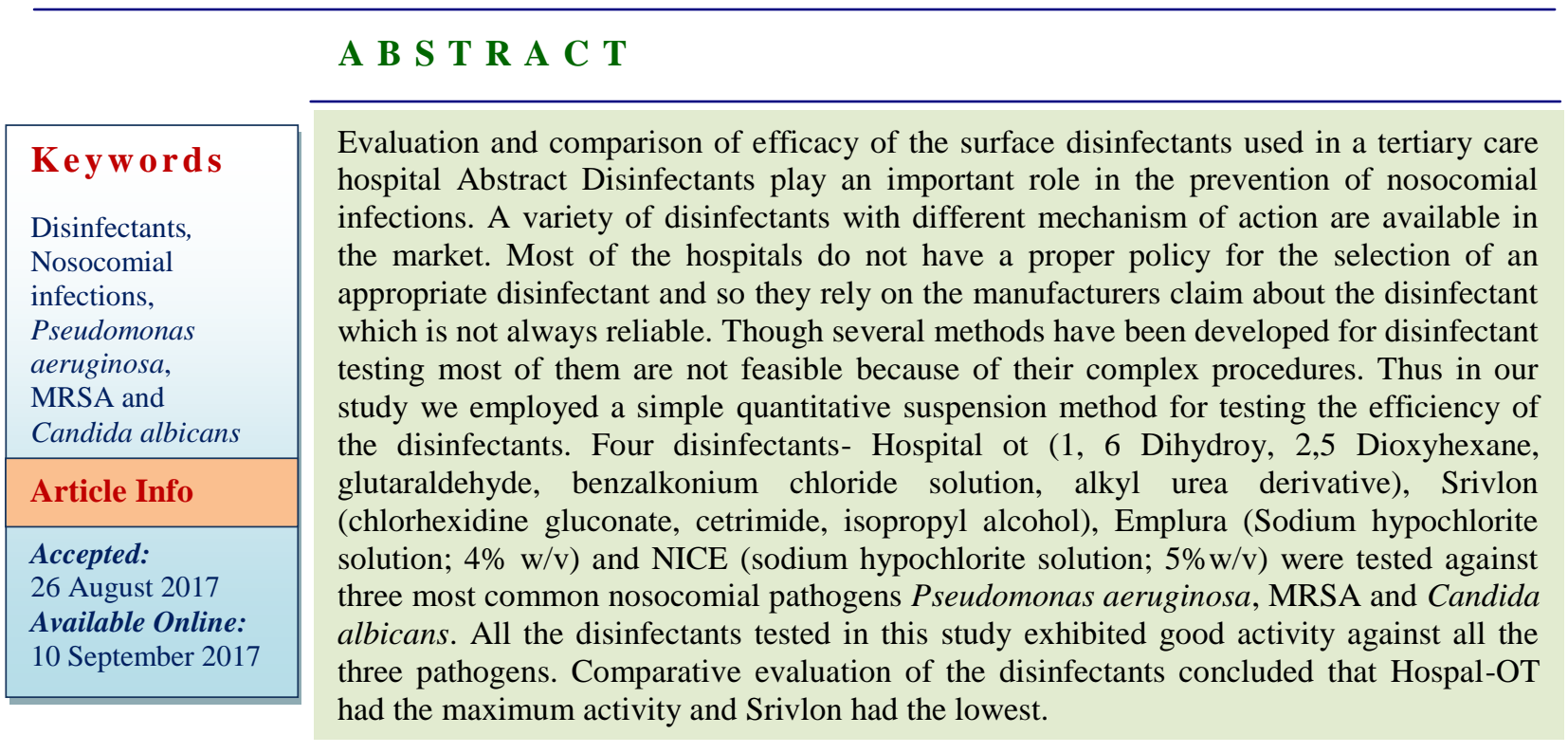

\section{Introduction}

Disinfectants form an integral part of infection control measures followed in a hospital. Their use helps in preventing acquisition and spread of hospital acquired infections. Surface disinfectants are used for disinfection of surfaces of the tables, bed railings, door handles, trolleys, walls and floors in OPD, ward and operation theatres.

Disinfection is described as a process that eliminates many or all pathogenic microorganisms, except bacterial spores, on inanimate objects (1).
Different classes of disinfectants are available based on their effectiveness against vegetative bacteria, tubercle bacilli, fungal spores, enveloped and non-enveloped viruses, and bacterial spores (2). Surface disinfectants commonly used in hospitals include sodium hypochlorite preparations, iodophors, quaternary ammonium compounds, phenolic compounds, bromides and disinfectants that are alcohol based.

Several factors affecting the efficacy of disinfectants include prior cleaning of the surface; organic and inorganic load present; type and load of microbial contamination; $\mathrm{pH}$ 
of the disinfectant, concentration of and exposure time to the disinfectant.

It is prudent to test disinfectants used in a health care setup periodically to ascertain their efficacy and potency. Various methodologies for testing disinfectants have been developed. The standard tests to check the efficiency of disinfection include RidealWalker phenol coefficient (R.W.C) test (3), Chick-Martin and Garrod's test (4), Kesley and Maurer's in-use tests, capacity use dilution test by Kelsey and Sykes (5) and microbial time kill assays (6).

These standard disinfection tests can also be classified as quantitative tests, semiquantitative tests, qualitative tests, or alternative tests. These tests are rarely followed in hospitals because of their complex procedure.

Many hospitals in India still do not have any standardised protocol for testing efficacy of disinfectants. Health care workers have limited awareness regarding choice of an appropriate disinfectant and so they rely on the literature provided by manufacturers which may not provide reliable data. With this back ground this study aims at performing 'quantitative suspension method' for testing efficacy of disinfectants used in our hospital.

The main aim and objectives of this study includes evaluating the efficacy of individual disinfectant against bacteria and fungi. Evaluation of the disinfectant activity against different contact time and also to compare the efficacy of different disinfectants.

\section{Materials and Methods}

This is an analytical study conducted in the department of Microbiology in a tertiary care hospital after being approved by the Institute Research and Ethics Committee.
The period of this study extended from August to September 2016.

\section{Disinfectants to be tested}

Hospal-OT (1, 6 Dihydroxy, 2, 5, Dioxyhexane, glutaraldehyde, benzalkonium chloride solution, alkyl urea derivative). Working solution made to $1 \%$.

Srilvon (chlorhexidine gluconate, cetrimide, isopropyl alcohol)

Emplura (Sodium hypochlorite solution; 4\% $\mathrm{w} / \mathrm{v})$

Diluted in a ratio of $1: 100$

NICE (sodium hypochlorite solution; 5\%w/v)

Diluted in a ratio of $1: 100$

Test organisms against which disinfectants were tested

Pseudomonas aeruginosa, Methicillin resistant Staphylococcus aureus, Candida albicans.

Hospital strains of all the above mentioned organisms obtained from our laboratory were used.

\section{Procedure used}

Quantitative suspension method (10)

\section{Methodology}

0.5 McFarland broth of the test organism suspension was prepared using normal saline. $0.1 \mathrm{ml}$ of this suspension was added to the 10 $\mathrm{ml}$ of disinfectant to be tested. All disinfectants were used at the concentration recommended by the manufacturer. After a specific contact time (5min, 10min, $20 \mathrm{~min}, 30$ $\mathrm{min}$ ), $1 \mathrm{ml}$ of this mixture was be transferred 
to the $9 \mathrm{ml}$ of neutralising solution (1\% sodium thiosulphate and $0.1 \%$ Tween 80).Approximately after $10 \mathrm{~min}, 1 \mathrm{ml}$ of suspension from the neutralizing tube was transferred to nutrient broth which was serially diluted $\left(1: 10,1: 10^{2}, 1: 10^{3}, 1: 10^{4}\right.$, $1: 10^{5}$ ) and $0.1 \mathrm{ml}$ from each dilution will be plated on nutrient agar plate using the spreadplate technique with the help of a sterile glass spatula.

Nutrient agar plates were incubated at $24 \mathrm{hr}$ and $48 \mathrm{hr}$ respectively. The test was performed thrice for each disinfectant. Controls for all the three organisms were put up by transferring $0.1 \mathrm{ml}$ of the $0.5 \mathrm{McF}$ arland broths of the test organisms to the diluents without disinfectant.

After incubation, the colonies present on the agar plates were counted and expressed as colony forming units (CFU) per millilitre. Efficacy of disinfectant was calculated using the formula:

Logarithmic Reduction Factor $(\mathrm{RF})=\log \mathrm{Nc}$ $-\log \mathrm{Nd}$

Nc: Number of colonies from control plates. $\mathrm{Nd}$ : Number of colonies from test plates

$\log _{10}$ reductions of 5 or more indicates satisfactory microbicidal activity i.e. at least $99.99 \%$ of the germs killed.

\section{Statistics}

Data were reported as logarithmic reduction in colony counts against different contact time. The data was analysed using the SPSS software utilising the Analysis of variance (one way ANOVA) test to evaluate whether the type of disinfectants and type of organism and used showed any statistically significant impact on reduction of colony counts.

\section{Results and Discussion}

The observations were expressed in terms of $\log _{10}$ reductions against different contact times and tabulated for comparison. Overall all four disinfectants used showed good microbicidal activity ( $\log 10$ reductions of more than 5 against all the three organisms tested). The analysis in this study showed that Hospal-OT were more effective on all the three organisms when compared to the other three disinfectants.

Srivlon was observed to have the lowest microbicidal activity. The microbicidal effect of all the disinfectants was observed to have increased on increasing the contact time from 5 to 10 minutes. Not much improvement in microbicidal activity was observed with subsequent increase in contact time (i.e., at 20min and $30 \mathrm{~min}$ ).

The hospital disinfectants play an important role in prevention of hospital acquired infections. Thus it is important to check the disinfectant efficacy before it is brought in use. In our study we performed the quantitative suspension test to evaluate the microbicidal activity of the disinfectants at different contact times and at their in-use concentration.

This test helped us in quantitatively assessing the decrease in the microbial load. The strains of bacteria used in this study represented the common nosocomial pathogens routinely isolated in our hospital. 
Table.1 Action of the test disinfectants against Pseudomonas aeruginosa

\begin{tabular}{|l|c|c|c|c|}
\hline \multirow{2}{*}{$\begin{array}{l}\text { Name of } \\
\text { disinfectant }\end{array}$} & \multicolumn{4}{|c|}{ Log reductions against different contact time } \\
\cline { 2 - 5 } & $\mathbf{5}$ $\mathbf{~ i n}$ & $\mathbf{1 0} \mathbf{~}$ in & $\mathbf{2 0}$ min & 30 $\mathbf{~ m i n}$ \\
\hline Hospal-OT 1\% & 6.67 & 8.53 & 8.53 & 8.53 \\
\hline Srivlon & 5.55 & 6.22 & 6.22 & 6.22 \\
\hline Emplura & 7.12 & 8.09 & 8.89 & 8.89 \\
\hline NICE & 7.02 & 8.01 & 8.01 & 8.01 \\
\hline
\end{tabular}

Table. 2 Action of the test disinfectants against Methicillin resistant Staphylococcus aureus

\begin{tabular}{|l|l|l|l|l|}
\hline \multirow{2}{*}{$\begin{array}{l}\text { Name of } \\
\text { disinfectant }\end{array}$} & \multicolumn{4}{|l|}{ Log reductions against different contact time } \\
\cline { 2 - 5 } & $\mathbf{5} \mathbf{~ m i n}$ & $\mathbf{1 0} \mathbf{~ m i n}$ & $\mathbf{2 0} \mathbf{~ m i n}$ & $\mathbf{3 0} \mathbf{~ m i n}$ \\
\hline Hospal-OT 1\% & 7.35 & 8.65 & 8.65 & 8.65 \\
\hline Srivlon & 5.05 & 6.12 & 6.14 & 6.14 \\
\hline Emplura & 7.29 & 8.21 & 8.21 & 8.21 \\
\hline NICE & 7.22 & 8.11 & 8.11 & 8.11 \\
\hline
\end{tabular}

Table.3 Action of the test disinfectants against Candida albicans

\begin{tabular}{|l|c|c|c|c|}
\hline \multirow{2}{*}{$\begin{array}{l}\text { Name of } \\
\text { disinfectant }\end{array}$} & \multicolumn{4}{|c|}{ Log reductions against different contact time } \\
\cline { 2 - 5 } & $\mathbf{5}$ $\mathbf{~ i n}$ & $\mathbf{1 0}$ $\mathbf{~ i n}$ & $\mathbf{2 0}$ min & 30 $\mathbf{~ m i n}$ \\
\hline Hospal-OT 1\% & 6.88 & 8.34 & 8.34 & 8.34 \\
\hline Srivlon & 5.45 & 6.33 & 6.36 & 6.36 \\
\hline Emplura & 7.88 & 8.17 & 8.17 & 8.17 \\
\hline NICE & 7.85 & 8.14 & 8.14 & 8.11 \\
\hline
\end{tabular}

Fig.1 Action of the test disinfectants against Pseudomonas aeruginosa

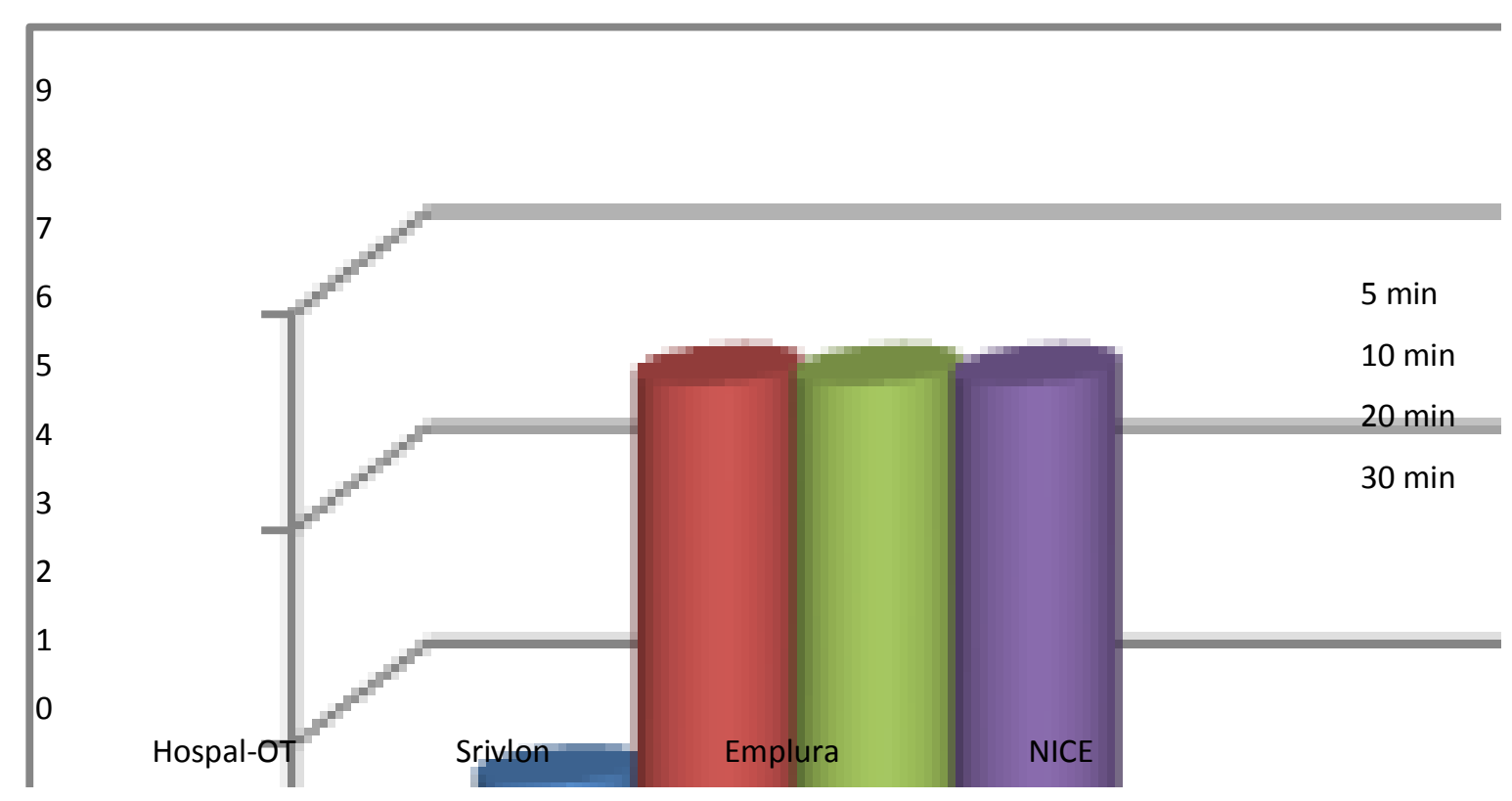


Fig.2 Action of the test disinfectants against Methicillin resistant Staphylococcus aureus

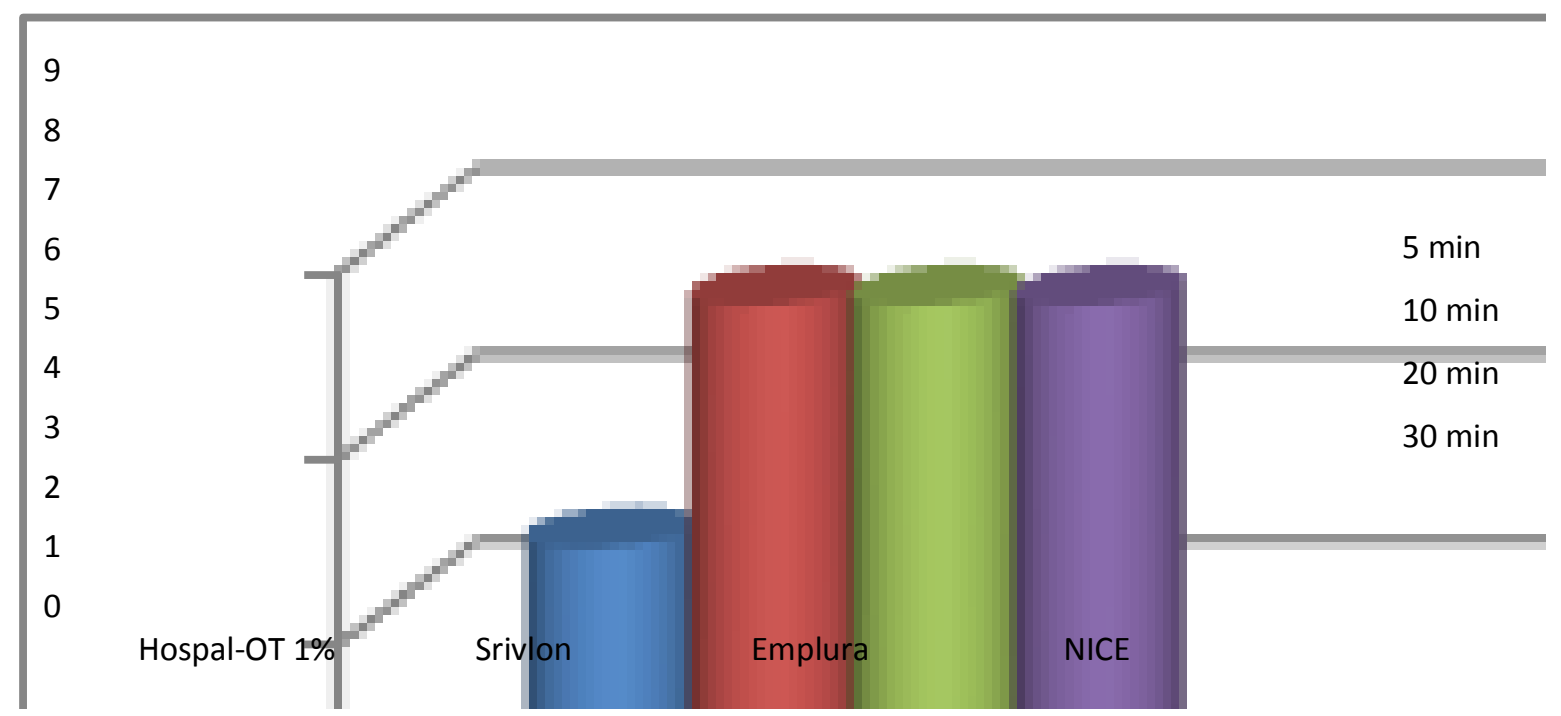

Fig.3 Action of the test disinfectants against Candida albicans

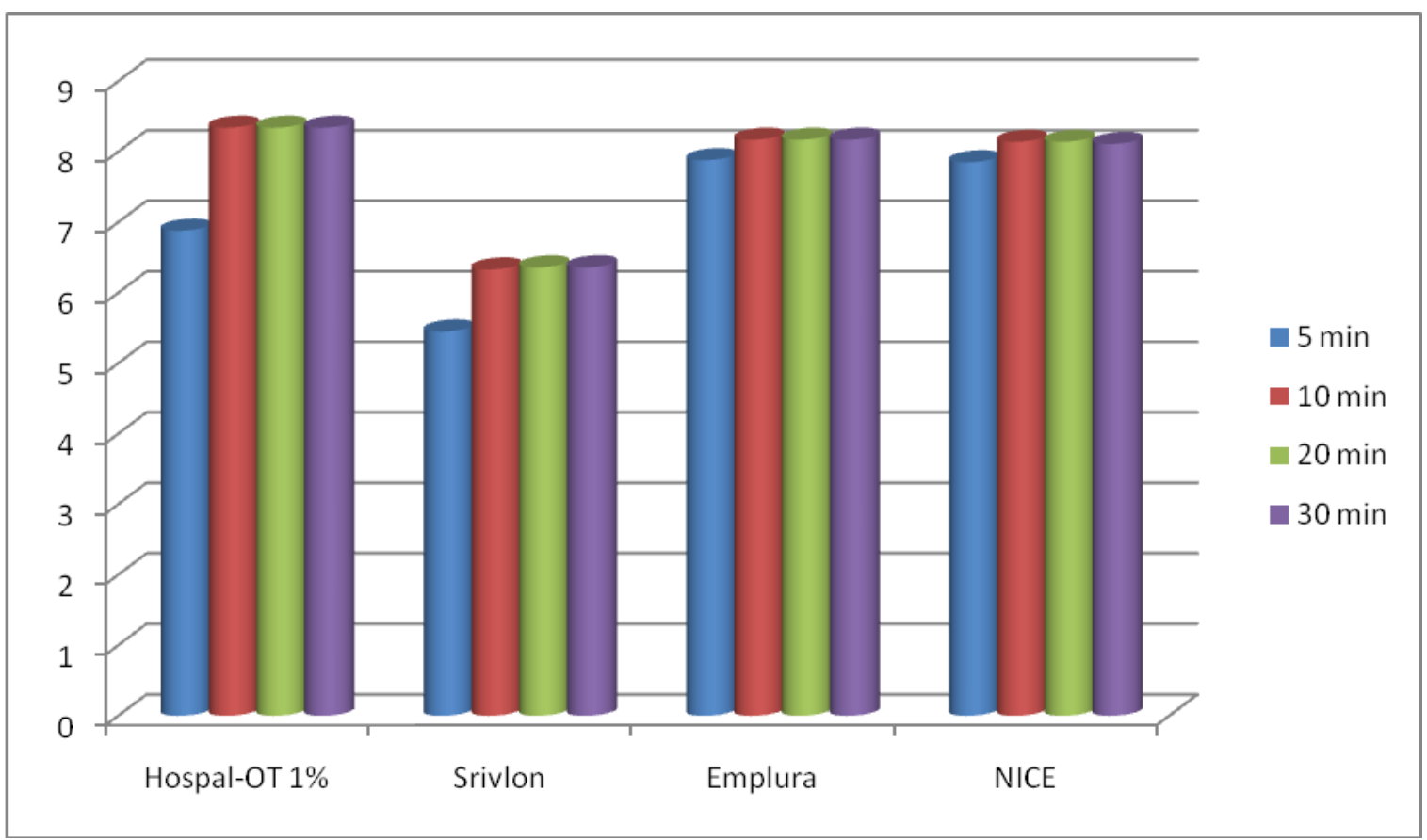

All the four disinfectants used in this study showed satisfactory microbicidal activity against all the three pathogens at different contact times. The comparative analysis in this study showed that Hospal OT had maximum killing effect on all the three pathogens $(\mathrm{P}<0.05)$ than the other three disinfectant. The highest logarithmic reduction due to Hospal OT in the microbial count was observed against MRSA (i.e., 8.65). The findings of our study also correlated with other studies performed on other disinfectants with same composition as that of Hospal- OT(i.e., 1, 6 Dihydroxy, 2-5 
Dioxahexane-11.2g, Glutaraldehyde-5.0g, Benzalkonium chloride-5.0g and Alkyl urea derivatives-3.0g)(11). Significant increase in the microbicidal activity was observed when the contact time was increased to 10 minutes but no significant increase $(\mathrm{P}>0.05)$ was observed thereafter with subsequent increase in contact times.

Both Emplura and NICE had fairly good microbicidal effect against all pathogen at different contact times at the routinely used concentration. The efficient disinfectant activity of sodium hypochlorite against bacteria, viruses and fungi has been well documented (12). In contrast to previous studies and literature(13), Srivlon (i.e., chlorhexidine gluconate, cetrimide, isopropyl alcohol) exhibited satisfactory but least microbicidal activity when compared to other three disinfectants. This could be possibly due to improper dilution or incorrect concentration details mentioned by the manufacturer.

Our study concluded that all the four disinfectants used in this study had broad activity against the pathogens Pseudomonas aeruginosa, MRSA and Candida albicans (Figs. 1-3 and Tables 1-3). The relatively poor performance of Srivlon emphasises the need for routine potency and efficacy testing of the disinfectants used in a hospital. Proper concentration and proper contact period is a must for efficient action of the disinfectant. Strict policy should be formulated for disinfectant selection and their use in order to curb the use of low quality and unauthorized disinfectants from local manufacturers.

\section{References}

1. Guideline for Disinfection and Sterilization in Healthcare Facilities, 2008 Disinfection_Nov_2008.pdf [Internet]. [cited 2016 Oct 1]. Available from: https://www.cdc.gov/hicpac/pdf/guidelines /Disinfection_Nov_2008.pdf

2. Grota, P., Ackiss EA, Association for Professionals in Infection Control and Epidemiology. APIC text of infection control and epidemiology. Washington, DC: APIC; 2014.

3. Rideal, S., Walker JTA. Approved technique of the Rideal-Walker test. Am J Public Health N Y N 1912. 1913 Jun; 3(6):575-81.

4. Garrod, L.P., A Study of the Chick-Martin Test for Disinfectants. J Hyg (Lond). 1934 Oct; 34(3):322-32.

5. Christensen, E.A., Jepsen OB, Kristensen $\mathrm{H}$, Steen G. In-use tests of disinfectants. Acta Pathol Microbiol Immunol Scand [B]. 1982 Apr; 90(2):95-100.

6. Kawamura-Sato, K., Wachino J, Kondo T, Ito $\mathrm{H}$, Arakawa $\mathrm{Y}$. Reduction of disinfectant bactericidal activities in clinically isolated Acinetobacter species in the presence of organic material. $\mathrm{J}$ Antimicrob Chemother. 2008 Mar; 61(3):568-76.

7. Reybrouck, G., Milestones in the testing of surface disinfectants: from Robert Koch to CEN TC 216. GMS Krankenhaushygiene Interdiszip. 2007 Sep 13 2(1). Available from:

http://www.ncbi.nlm.nih.gov/pmc/articles/ PMC2831497/

8. Kelsey, J.C., SG. A new test for the assessment of disinfectants with particular reference to their use in hospitals. Pharm J. 1969; (202):607-609.

9. Van Klingeren, B., Disinfectant testing on surfaces. Journal of Hospital Infection. 1995 Jun; 30:397-408.

10. Hernández, A., Martró E, Matas L, Ausina V. In-vitro evaluation of Perasafe ${ }^{\circledR}$ compared with $2 \%$ alkaline glutaraldehyde against Mycobacterium spp. J Hosp Infect. 2003 May; 54(1):52-6.

11. I.NK, Kulkarni M, B HB. Selection and microbial control of disinfectants and 
validation of disinfectant microbial efficacy in the pharma and biopharmaceutical industry: a case study. Int J Bioassays. 2014 May 3; 3(5): 207982.

12. Fukuzaki, S., Mechanisms of actions of sodium hypochlorite in cleaning and disinfection processes. Biocontrol Sci. 2006 Dec; 11(4): 147-57.

13. GIO, JAA, AAA. Comparative Antimicrobial Activity of Commercial Disinfectants with Naphtholics. Res J Microbiol. 2008 Apr 1; 3(4): 262-8.

\section{How to cite this article:}

Namrata K. Bhosale. 2017. Evaluation and Comparison of Efficacy of the Surface Disinfectants Used in a Tertiary Care Hospital. Int.J.Curr.Microbiol.App.Sci. 6(9): 2608-2614. doi: https://doi.org/10.20546/ijcmas.2017.609.321 